\title{
Phellodendron amurense Bark Extract
}

National Cancer Institute

\section{Source}

National Cancer Institute. Phellodendron amurense Bark Extract. NCI Thesaurus. Code C103230.

A proprietary formulation consisting of a Phellodendron amurense (Amur cork tree) bark extract, often used in traditional Chinese medicine, with anti-inflammatory, anti-oxidant and potential chemopreventive and antineoplastic activities. Phellodendron amurense bark extract contains certain isoquinoline alkaloids, flavone glycosides and phenolic compounds. Upon administration of Phellodendron amurense bark extract, the various phytochemicals in this formulation modulate multiple signal transduction pathways. This agent appears to block the activation of the transcription factor cAMP response binding protein (CREB) and inhibits Akt signaling, thereby inhibiting tumor cell growth and inducing apoptosis in Akt- and CREB-overexpressing cancer cells. In addition, this agent inhibits cyclooxygenase type 2 (COX-2), nuclear factor kappa b (NF-kB) and tumor necrosis factor alpha (TNF-a)-mediated signaling; COX-2, NF-kB and TNF-a are upregulated in certain types of cancer and during inflammation. 